\title{
Reconstruction of Heel: Options and Strategies
}

\author{
MA Kalama, SR Faruquee ${ }^{\mathrm{b}}$, SA Rahman ${ }^{\mathrm{c}}, \mathrm{HN} \mathrm{Uddin}^{\mathrm{d}}$
}

\section{Summary:}

Soft tissue loss at the weight bearing part of heel is frequently caused by trauma, infection, tumor and burn. Reconstruction becomes a challenge due to limitation of available similar or near similar tissues. Sensation of weight bearing heel is an important consideration prior to reconstruction, also the intact Posterior Tibial arterial blood flow, which becomes the dominant artery for the sole of the foot. We have done heel reconstruction of 30 patients with the Medial Plantar Island flap and 50 patients with Superficial Sural Island flap. Results were very much encouraging in terms of flap survival, durability of coverage and functional outcome. Twenty nine cases of Medial Plantar Island flap survived with excellent weight-bearing function. Among the Medial Plantar Island flap group one flap was lost due to vascular insufficiency in a diabetic patient. All the 50 cases (100\%) of Superficial Sural Island flap survived without any flap loss. These flaps need about two years time for adaptive changes to become a smooth weight bearing heel. During this period the reconstructed heel needs to be supported by heel pad or modified shoes. Our study has shown that Medial Plantar Island flap and Superficial Sural Island flap are the two armamentarium for reconstruction of the weight-bearing heel in about all cases of heel defects with excellent to better reconstructive and functional outcome.

\section{Introduction:}

Heel is the important integrated part of the sole of the foot which is essential for smooth walking. Without heel the propelling function of the foot during walking is severely interrupted. Trauma is the leading cause of soft tissue loss of the heel followed by tumor, infective gangrene and burn. Most of the cases of isolated soft tissue injuries result from degloving type of injury in which, after wound excision, immediate reconstruction can be performed with Medial Plantar Island flap ${ }^{1,2}$. Trauma may involve only the soft tissue but, majority of the time may be associated with fracture of one or more bones which is complicated by exposed tendoachilles adjacent to heel. More over,

a. Prof. Md. Abul Kalam, Professor and Head, Department of Burn, Plastic and Reconstructive Surgery, Shaheed Shurawardy Medical College \& Hospital, Dhaka.

b. Dr. Sajdur Reza Faruquee, Jr consultant Ortho, Hand and Trauma Rreconstructive Surgeon

c. Dr. Sharif Ashfia Rahman Jui, Resident Surgeon (casualty), Shaheed Shurawardy Medical College \& Hospital, Dhaka.

d. Dr. Hasan Naziruddin, Resident, Department of Plastic Surgery, NITOR

Address of correspondence : Prof. Md. Abul Kalam, Professor and Head, Department of Burn, Plastic and Reconstructive Surgery, Shaheed Shurawardy Medical College \& Hospital, Dhaka, Mobile: +880 1713001059 fracture of bones may cause injury of Posterior Tibial artery which prevents the reconstruction by Medial Plantar Island flap. Then Superficial Sural Island flap ${ }^{3}$ is the option for coverage. Every resurfacing needs to be tailored according to the need. We have done heel reconstruction with the Medial Plantar Island flap in 30 cases and with Superficial Sural Island flap ${ }^{3}$ in 50 cases. In this paper we have discussed the different scenarios and optiond for flaps as well as strategies for heel reconstruction.

\section{Materials and methods:}

Total eighty patients with soft tissue loss from weightbearing heel were treated in the plastic surgery department of NITOR and Samorita Hospitals in Dhaka from January 2004 to December 2009. Out of these eighty patients, thirty patients were treated with Medial Plantar Island flap and fifty patients with Superficial Sural Island flap.

Medial Plantar island flap was done on patients whose defects were between $5 \mathrm{~cm}$ to $8 \mathrm{~cm}$ in length and breadth, instep area of the sole of the foot is intact and Posterior Tibial artery with its continuation into the Medial Plantar artery is patent. Superficial Sural island flap was done on patients whose defect were $9 \mathrm{~cm}$ to $15 \mathrm{~cm}$ in length and $5 \mathrm{~cm}$ to $10 \mathrm{~cm}$ in breadth and no injury on the lateral aspect of the lower third of the leg which could interrupt the vascularity of the flap.

Majority of the patients were male with age range 
between 15 to 55 years. Age distribution is described in table-I.

Table-I: Age distribution of patients $(n=80)$

\begin{tabular}{|c|c|}
\hline Age of patient years & No of patients $\%$ \\
\hline $15-25$ years & $20(25 \%)$ \\
\hline $25-35$ years & $45(57 \%)$ \\
\hline $35-55$ years & $15(18 \%)$ \\
\hline
\end{tabular}

Trauma is the main cause of the soft tissue loss of heel in our series. The etiology is shown in Table-II.

Table-II: Etiology of heel defect $(n=80)$

\begin{tabular}{|c|c|}
\hline Etiology & No of patients $\%$ \\
\hline Trauma & $60(75 \%)$ \\
\hline Tumor & $08(10 \%)$ \\
\hline Infective gangrene & $08(10 \%)$ \\
\hline Burn & $04(15 \%)$ \\
\hline
\end{tabular}

All the wounds were prepared by wound excision, antibiotics administered according to culture and sensitivity test and dressing. When the wound were adequately prepared they were resurfaced with flaps.

\section{Procedure for medial plantar island flap:}

Shanahan and Gingrass in 1979 described Medial plantar sensory flap for coverage of heel defects'. Later Harrison and Morgan in 1981 described island fasciocutaneous version of the flap2. The flap is designed by a template made according to the defects (Fig-1).

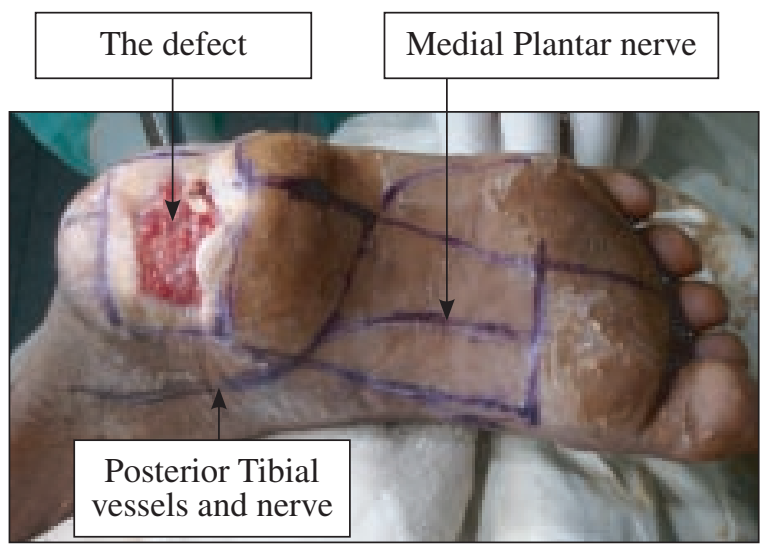

Fig-1: Marking for Medial Plantar flap

The flap is raised from distal to proximal and including the plantar fascia. The incision is made at the borders of the designed flap and extends through the planter fascia between the abductor hallucis muscle and first slip of the flexor digitorum brevis muscle. At the distal end of this incision medial plantar artery with its venae comitants and medial plantar nerve are identified and dissected proximally beneath the flap up to the defect in the heel or up to the tuberosity of the calcaneous. Then the flap is transposed and set on the defect (Fig-2).

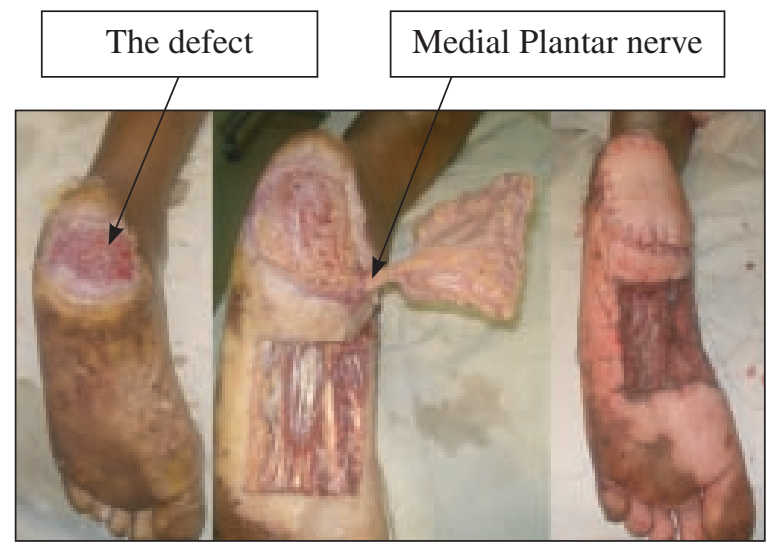

Fig-2: Medial Plantar Island flap

Donor site of the flaps were primarily grafted with split-thickness skin graft (fig-2). All these twenty nine cases of medial plantar island flap healed uneventfully along with their donor sites and functional outcome was satisfactory.

\section{Procedure for sural island flap:}

Superficial Sural island flap $^{3}$ was described by Masqulet in1992. It is a fasciocutaneous island flap taken from the posterior aspect of the middle third of the leg (Fig-3).

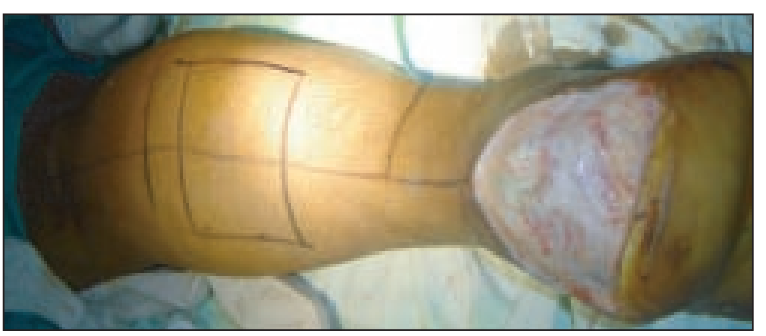

Fig-3 : Sural Island flap landmarks

Superficial Sural island flap based on very small leash of blood vessels accompanying the Sural nerve which communicate distally with the septocutaneous branch of the peroneal artery near the lateral malleolus. It is mandatory to keep the pedicle's breadth at least $3 \mathrm{~cm}$ 
and must contain both short saphenous vein and sural nerve. The dissection starts from proximal to distal and must include the deep fascia at all margins (Fig-4).

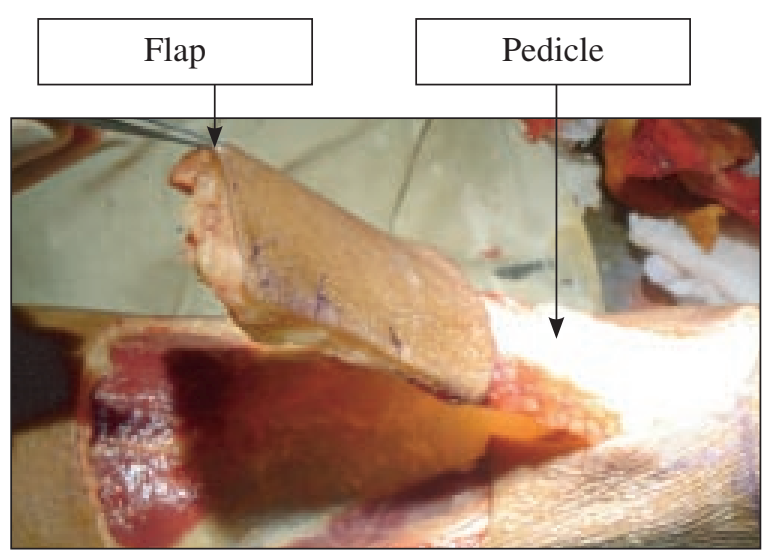

Fig-4 : sural island flap raised

Superficial sural vessels are identified along with the sural nerve between two heads of the gastrocnemius muscle in the proximal part of the flap and between sural nerve and short saphenous vein in the distal part of the flap. The flap is raised up to the level of $6 \mathrm{~cm}$ proximal to the lateral malleolus and then transposed to cover the heel defect (Fig-3). Donor site of the flaps were primarily grafted with split-thickness skin graft (Fig-5). Though superficial sural flap provided adequate soft tissue padding for weight-bearing heel, it requires constant foot care when patient starts standing and walking.

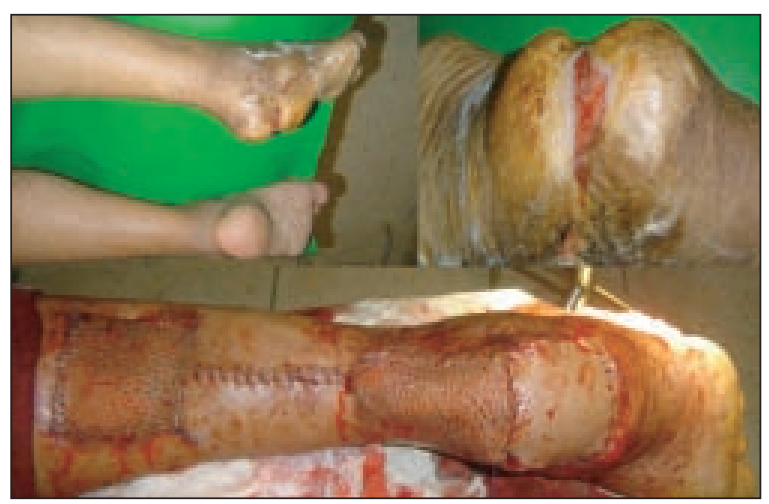

Fig-5 : Sural island flap covering the defect of heel

\section{Complications:}

One case of medial plantar island flap has been lost because of compression of pedicle within the tunnel in the post-operative period. This complication can be avoided by constant monitoring of the flap in the post operative period and removing the skin stitches over the tunnel when it shows the sign of ischemia. This was subsequently managed by superficial sural island flap.

Table III: Complications:

\begin{tabular}{|c|c|c|c|c|}
\hline \multirow{2}{*}{ Flap } & \multirow{2}{*}{ Survival } & \multicolumn{3}{|c|}{ Necrosis } \\
\cline { 3 - 5 } & & Marginal & Partial & Total \\
\hline Medial Plantar Island flap n=30 & 29 & Nil & Nil & 01 \\
\hline Superficial Sural Island flap $\mathrm{n}=50$ & 45 & 03 & 02 & Nil \\
\hline
\end{tabular}

Forty five superficial sural island flaps survived without any flap loss, three flaps had distal marginal necrosis which was managed by excision followed by secondary stitches. In two cases the distal third of the flaps were lost due to inadequate post operative management (direct pressure over the pedicle) and needed excision of the devitalized part of the flap followed by closure of the defect with alternative procedures like flap advancement and skin grafting.

\section{Results:}

Results were measured in terms of flap survival and functional outcome i.e. uneventful walking, and were graded as excellent, good and poor. Criteria for excellent results were survival of flaps without any flap loss and walking without any aids i.e. artificial heel pads or foam padded shoes. Survival of flap with minimum complications and walking with aids were the criteria for good results. Poor result is said when an alternative reconstructive procedure was required.

\begin{tabular}{|c|c|l|l|}
\hline \multirow{2}{*}{ Name of flap } & \multicolumn{3}{|c|}{ Criteria } \\
\cline { 2 - 4 } & $\begin{array}{l}\text { Excellent: } \\
\text { Flap survived, } \\
\text { no walking aids }\end{array}$ & $\begin{array}{l}\text { Good: } \\
\text { flap survived } \\
\text { minor complication, } \\
\text { walking aids }\end{array}$ & $\begin{array}{l}\text { Poor: } \\
\text { alternative } \\
\text { reconstruction } \\
\text { procedure required }\end{array}$ \\
\hline Medial plantar island flap & 29 & & 01 \\
\hline Superficial Sural island flap & & 48 & 02 \\
\hline
\end{tabular}

In medial plantar island flap group, excellent results were obtained in twenty nine cases and poor result in one. In superficial sural island flap group good results were observed in forty eight patients and poor results in two.

\section{Discussion:}

Reconstruction of the heel is a difficult problem to deal with particularly in a developing country like Bangladesh, where a large number of patients adds everyday to reconstructive ladder in spite of poor infra-structural facilities and resource constraints. Flap reconstruction of heel defect encounters serious 
obscurity because of unavailability of similar or near similar tissues and vascular axis for local flap. There are several ways and options to overcome the problem of heel coverage. The techniques were applied for heel coverage starting from skin graft $^{4,5}$, to numerous types of flaps including muscle flaps ${ }^{6,7}$ septocutaneous flaps $^{8,9}$, axial flaps ${ }^{10}$ and free flaps ${ }^{11,12,13}$. Skin graft breaks up on repeated stress of weight bearing. Other flaps are often short of length to cover the whole heel. 'Free flap' is also very technically demanding option for reconstruction of heel. It becomes more bulky than usual, requires high grade of expertise and infrastructural support. Initially it is insensate, requires more time for adaptive changes of weight bearing heel and achieving sensation. Moreover, incidence of flap loss is about $8 \%$ in an expert centre. Free flap is also discouraged in case of diabetes by some author ${ }^{14}$ for comorbity and complication of prolonged operation. But it is of great value when no other local flap is available for reconstruction of heel. Distally based fasciocutaneous flap may be an option but it is a two stage surgery, vascularity is not that much reliable as that of other random pattern flap. Random pattern flaps can be raised but they have high incidence of failure ${ }^{15}$.

Cross leg flap may be an extreme end of the options where all local flaps are not available and facilities for doing free flaps are absent. It is a two stage surgery carrying significant morbidity as patient's both legs are attached with each other by the flaps, needs to stay in the hospital for more than three weeks and joints of the leg tend to become stiff. Despite its primitiveness, it is still very useful in some situation in the developing countries, where reconstructive surgery is yet to developed.

Most of the patient in our series are young adults in their active life and loses their weight-bearing heel due to trauma. This is favorably compared to the study carried in the subcontinent $t^{16,17}$. In case of traumatic loss the option of flap depend on the size of the defect and associated fractures and availability of vascular pedicle. In this series small defect $(5 \mathrm{~cm}$ to $8 \mathrm{~cm}$ in length and breadth) were covered with medial planter island flap and in larger defects sural island flaps were used. There was not much difference in the procedural aspect as both are island flaps with good arc of rotation. ${ }^{17}$

Next common cause of soft tissue loss of weightbearing heel is due to excision of tumor. Malignant melanoma is the common tumors in our series five in number followed by squamous cell carcinoma which is three in number. Both the tumor required wide excision for the tumor free margin followed by reconstruction. In our study only one case after excision of critical area was $8 \mathrm{~cm}$ long so sural island flap was used, the rest were covered with Medial plantar flap.

Infective gangrene of soft tissue of the heel is usually a difficult problem for reconstruction because of late presentation, dealt initially by non-plastic surgeons and tissue destruction is more extensive. The scenario often complicated by the presence of diabetes. An aggressive wound excision followed by appropriate antibiotics according to culture and sensitivity test is essential prior to reconstruction. Vascular insufficiency is another problem in this group of patients. Many procedures have been described for resurfacing heel of diabetic patient but axial pattern flaps are suitable and effective. Sural island flap can be delayed for better vascularity in diabetic patient. ${ }^{18}$

Medial plantar flap is the flap of choice in terms of sensation and early ambulation. ${ }^{15,17}$

Full-thickness burn is another important cause of soft tissue loss from the heel region. Depending on the size of the defect, flaps were chosen but there was no significant difference in the outcome.

We have chosen these two flaps for reconstruction of weight-bearing heel, one is medial plantar island flap and the other is superficial sural island flap according to the size of defect. Medial plantar island flap is selected for those cases in whom the defect is within $5 \mathrm{~cm}$ to $8 \mathrm{~cm}$ with intact instep area of the sole and medial plantar artery is patent. Superficial sural island flap is reserved for larger defects, with injury to the instep area of sole and patency of medial plantar artery is absent or doubtful.

In our series thirty heels were reconstructed with medial plantar island flap, of which excellent results were obtained in twenty nine cases and poor in one case. Fifty heels were reconstructed in our series with superficial sural island flaps, excellent result not obtained in any patient, good result obtained in forty eight patients and poor in two patients. We have lost one medial plantar island flap managed by sural island flap. There was partial loss in two superficial sural island flap group managed by alternative method of reconstruction (skin grafting and advancement). Flap survival as comparable to other series ${ }^{14-18}$. 
Of all the options for reconstruction of heel medial plantar island flap is the best one, in terms of tissue type, texture, and function ${ }^{16,17}$. Superficial sural island flap is fasciocutaneous in nature but very versatile in terms of movement and vascularity. Its arc of rotation is $180^{\circ}$, and provides adequate coverage of proximal and distal heel without kinking of the vascular pedicle. The shortcoming of this flap in respect to heel coverage is it is insensate and tissue type is not similar to that of the heel. Adaptive alteration overcomes this limitation. It requires about one to one and half year to gain adaptive changes of weight bearing heel and protective sensation. Moreover, it is a very simple procedure which can be done in any centre with an average technical expertise. In a comparative study between medial plantar island flap and superficial sural island flap for heel coverage revealed no significant

\section{References:}

1. Shanahan RE, Gingrass RP. Medial plantar sensory flap for coverage of heel defects. Plast Reconstr Surg, 1979; 64(3):295-8.

2. Harrison DH, Morgan BDG. The instep island flap to resurface plantar defects. Br J Plast Surg, 1981; 34:31518.

3. Masquelet AC, Romana MC and Wolf G. Skin island flaps supplied by vascular axis of the sensitive superficial nerves: Anatomic study and clinical experience in the leg. Plast Reconstr Surg, 1992; 89:1115-1121.

4. Lister GD. Use of an innervated skin graft to provide sensation to the reconstructed heel. Plast Reconstr Surg, 1978; 62:157.

5. Maquieira NO. An innervated full-thickness skin graft: To restore sensibility to finger tips and heels. Plast Reconstr Surg, 1974; 53: 568.

6. Hartrampf CRJ, Scheflan M and Bostwick J. The flexor digitorum brevis muscle island flaps. A new dimension in heel reconstruction. Plast Reconstr Surg, 1980; 66:264.

7. Townsnd PLG. An inferiorly based soleus muscle flap. $\mathrm{Br}$ J Plast Surg, 1978; 31:210.

8. Yoshimura M, Imura S, Shimamura K, Yamauchi S and Nomura S. Peroneal flap for reconstruction in the extremity: Preliminary report. Plast Reconstr Surg, 1984; 74: 402.

9. Chang SM, Zhang F, Yu GR, Hou GL et al. Modified distally based peroneal artery perforator flap for reconstruction of foot and ankle. Br J Plast Reconstr Surg, 2004; 24:430.

10. Voche P, Merle M and Stussi JD. Lateral supra-malleolar flap: Experience with 42 flaps. Ann Plast Surg, 2005; 54: 49.

18 difference in flap survival. The only difference was in early weight bearing in case of medial plantar flap ${ }^{17}$.

Medial plantar island flap is an excellent flap for small defects which provides the similar tissue of the heel, and preserves all the function in the post-reconstructive period. Superficial sural island flap is an alternative for large defects and provides relatively better functional heel. So these two flaps almost fulfill the requirements of heel reconstruction which can be tailored according to need.

\section{Conclusion:}

Our study has shown that Medial plantar island flap and Superficial sural island flap are the two armamentarium for reconstruction of the weight-bearing heel in about all cases of heel defects with excellent to better reconstructive and functional outcomes.

11. Meland NB. Microsurgical reconstruction: The weight bearing surface of the foot. Ann Plast Surg, 1990;11: 54.

12. Goldberg JA, Adkin P and Tsai TM. Microvascular reconstruction of the foot: weight-bearing pattern gait analysis and long-term follow up. Plast Reconstr Surg, 1993;92: 904

13. Chen SL, Chuang CJ, Chou TD, Chen TM and Wang HJ. Free medial sural artery perforator flap for ankle and foot reconstruction. Ann Plast Surg, 2005; 54: 39.

14. Demiri E, Dionyssiou D, Antoniou A, Kakas P, Hantes A, Forglou P and Lazaridis L. The use of pedicle island axial flap for reconstruction of diabetic foot defects. Aristotle university M J. 2006; 33(1):93-99.

15. Eldin AB, Elbassoni L and Elhddy A. Distally Based Sural Fasciocutaneous Flap for Coverage of Foot Defects. Egypt, J Plast Reconstr Surg, July 2006; 30(2):93-99.

16. Pirwani MA, Samo S, Soomro YH. Distally based sural artery flap: A workhorse to cover soft tissue defects of lower 1/3rd tibia and foot, Pak J Med Sci. 2007; 23(1):103-7.

17. Rashid M, Hussain S, Aslam R, Illahi IA. comparison of two Fasciocutaneous Flaps in the reconstruction of defects of the weight - bearing heel. Coll Physicians Surg Pak. Apr 2003; 13(4):216-8.

18. Tosum Z, Ozkam A, Karacoz Z, Savci N. Delaying the reverse sural flap provides predictable result for complicated wounds in diabetic foot. Ann Plast Surg. 2005; 55:169-173 